\title{
APLIKASI PEMBELAJARAN CLASS DIAGRAM BERBASIS WEB UNTUK PENDIDIKAN REKAYASA PERANGKAT LUNAK
}

\author{
Egia Rosi Subhiyakto \\ Fakultas Ilmu Komputer, Program Studi Teknik Informatika \\ Universitas Dian Nuswantoro \\ Email: egia@dsn.dinus.ac.id \\ Yani Parti Astuti \\ Fakultas Ilmu Komputer, Program Studi Teknik Informatika \\ Universitas Dian Nuswantoro \\ Email: yani.parti.astuti@dsn.dinus.ac.id
}

\begin{abstract}
ABSTRAK
Tahapan pembangunan perangkat lunak atau lebih dikenal dengan istilah SDLC (Software Development Life Cycle) memiliki beberapa tahapan termasuk tahapan analisis. Dalam tahap analisis pemodelan ke dalam bentuk diagram biasanya dilakukan secara mendalam untuk memodelkan masalah yang dihadapi. UML merupakan bahasa de facto dalam pemodelan kebutuhan perangkat lunak berorientasi objek. Aplikasi pemodelan yang berkembang mayoritas lebih ditujukan untuk dunia industri serta memerlukan instalasi dan lisensi yang terbatas. Penelitian ini mengembangkan sebuah aplikasi pemodelan kebutuhan perangkat lunak khususnya pemodelan class diagram. Aplikasi dikembangkan berbasis web, sehingga tidak perlu ada instalasi dan tidak perlu membayar lisensi. Fitur yang dikembangkan yakni pengenalan notasi-notasi class diagram beserta penjelasannya. Aplikasi juga menyediakan area kerja untuk menggambarkan diagram beserta fitur cetak hasil diagram yang telah dibuat. Aplikasi dikembangkan menggunakan metode pengembangan prototyping, sehingga didapatkan prototipe aplikasi. Prototipe aplikasi dapat terus dikembangkan sehingga mendapat hasil yang maksimal. Hasil pengujian fungsionalitas menggunakan metode pengujian black box didapatkan bahwa 100\% fungsi berjalan dengan baik. Sedangkan pengujian user acceptance dengan tiga parameter didapatkan bahwa $92 \%$ responden setuju bahwa aplikasi memiliki kinerja yang baik, 90\% responden setuju aplikasi mudah digunakan dan $89 \%$ responden puas terhadap aplikasi yang dibangun.
\end{abstract}

Kata kunci: UML; diagram; class; prototipe; aplikasi.

\section{ABSTRACT}

The stages of software development or better known as SDLC (Software Development Life Cycle) have several stages including the stages of analysis. In the analysis stage modeling in the form of diagrams is usually done in-depth to model the problem at hand. UML is a de facto language in modeling object-oriented software requirements. Application modeling that is developing today is more aimed at the industrial world and only a few parts that accommodate the world of education. This research develops a software requirements modeling application especially class diagram modeling. The application is developed based on the web, so there is no need for installation and no need to pay a license. The feature developed is the introduction of class diagram notations and their explanations. The application also provides a work area to illustrate the diagram along with the printed features of the diagram results that have been made. The application was developed using the prototyping development method so that an application prototype is obtained. The application prototype can be developed so that it gets maximum results. The results of testing the functionality using the black box testing method found that $100 \%$ of the functions run well. While user acceptance testing with three parameters found that $92 \%$ of respondents agreed that the application had good performance, $90 \%$ of respondents agreed that the application was easy to use and 89\% of respondents were satisfied with the application built.

Keywords: UML; diagram; class; prototype; application.

\section{PENDAHULUAN}

Pengembangan perangkat lunak biasanya terbagi menjadi 2 bagian yakni tujuan industri dan tujuan pendidikan. Perangkat lunak yang ditujukan untuk dunia industri tergolong kompleks dan biasanya berbayar. Sedangkan untuk dunia pendidikan, pengembangan perangkat lunak relatif lebih sederhana agar mudah dipahami oleh mahasiswa. Mahasiswa yang mempelajari dunia rekayasa perangkat lunak biasanya tergolong sebagai pengembang perangkat lunak pemula atau novice developer. Pengetahuan mengenai pengembangan perangkat lunak wajib dimiliki oleh mahasiswa agar menjadi pengembang perangkat lunak yang memiliki kompetensi [1]. 
Tahapan pengembangan perangkat lunak meliputi komunikasi, perencanaan, pemodelan, konstruksi dan deployment [2]. Tahap pemodelan merupakan bagian inti dalam memodelkan masalah maupun solusi perangkat lunak yang akan di bangun.

UML telah menjadi standar de facto bahasa pemodelan perangkat lunak berorientasi objek. Aplikasi pemodelan yang digunakan banyak jenisnya, perbandingan aplikasi pemodelan UML telah dilakukan oleh [3] yang membandingkan aplikasi seperti Rational Rose, ArgoUML, MagicDraw, dan Enterprise Architect. Sedangkan dalam [4] juga membandingkan aplikasi seperti Rational Rose, Enterprise Architect, MS. Visio, Magic Draw, UMLet, STORM, dan RMTool. Dari hasil perbandingan didapatkan bahwa mayoritas aplikasi ditujukan untuk dunia industri dan berbayar. Pengembangan aplikasi pemodelan kebutuhan perangkat lunak telah dilakukan oleh beberapa peneliti, diantaranya adalah [5] yang mengembangkan sebuah alat pemodelan UML berbasis web dengan menggunakan metode SCRUM, alat yang dikembangkan tidak membutuhkan instalasi dan spsesifikasi yang cukup ringan agar dapat menggunakan aplikasi. Penelitian lain dalam [6] mengembangkan sebuah LogViz untuk memantau aktifitas mahasiswa dalam merancang UML.

Penelitian yang dilakukan merupakan hasil pengembangan dari penelitian terdahulu yang memiliki keterbatasan dalm hal diagram yang dimodelkan. Jika sebelumnya hanya use case diagram pada penelitian kali ini adalah mengembangkan aplikasi pemodelan class diagram berbasis web sebagai solusi dari kompleksitas dan lisensi yang berbayar dari aplikasi pemodelan yang telah ada. Aplikasi dikembangkan khusus untuk memodelkan diagram kelas yang ada dalam UML. Aplikasi memiliki fitur pengenalan notasi-notasi class diagram beserta penjelasannya. Aplikasi juga menyediakan area kerja untuk menggambarkan diagram beserta fitur cetak hasil diagram yang telah dibuat. Aplikasi dikembangkan dalam platform web, sehingga tidak perlu proses instalasi dan mudah diakses.

\section{METODOLOGI PENELITIAN}

Tahapan penelitian mencakup lima tahapan seperti yang terdapat dalam gambar 1. Tahap penelitian dapat dijelaskan sebagai berikut:

Masalah yang dihadapi adalah aplikasi pemodelan yang tersedia di pasaran relatif kompleks dan berbayar. Hal tersebut menjadi alas an utama kami mengembangkan aplikasi pemodelan yang gratis dan mudah dipahami. Aplikasi yang dibangun nantinya berbasis web dan tidak perlu instalasi. Tujuan penelitian ini adalah mengembangkan aplikasi pemodelan kebutuhan perangkat lunak khususnya class diagram. Aplikasi berbasisis web dibangun menggunakan bahasa pemrograman PHP, HTML dan CSS. Terdapat fitur penjelasan notasi class diagram dan terdapat area kerja untuk membuat diagram serta fitur pencetakan diagram. Untuk studi literatur digunakan untuk mencari materi terkait dengan pemodelan kebutuhan perangkat lunak khususnya class diagram. Terdapat beberapa jurnal, buku dan dokumen prosiding yang digunakan sebagai literatur.

Fase implementasi dilakukan dengan menggunakan perangkat lunak pendukung seperti XAMPP, Sublime text, dan notepad ++. Sedangkan untuk bahasa pemrograman menggunakan PHP, HTML, dan CSS. Aplikasi dibuat menjadi prototipe yang dapat di evaluasi oleh pengguna secara langsung. Uji coba prototipe dilakukan oleh pengguna secara langsung, apabila terdapat kekurangan berdasarkan hasil evaluasi maka akan dilakukan perbaikan. Evaluasi prototipe untuk memastikan kinerja aplikasi, kemudahan penggunaan dan tingkat kompleksitas aplikasi.

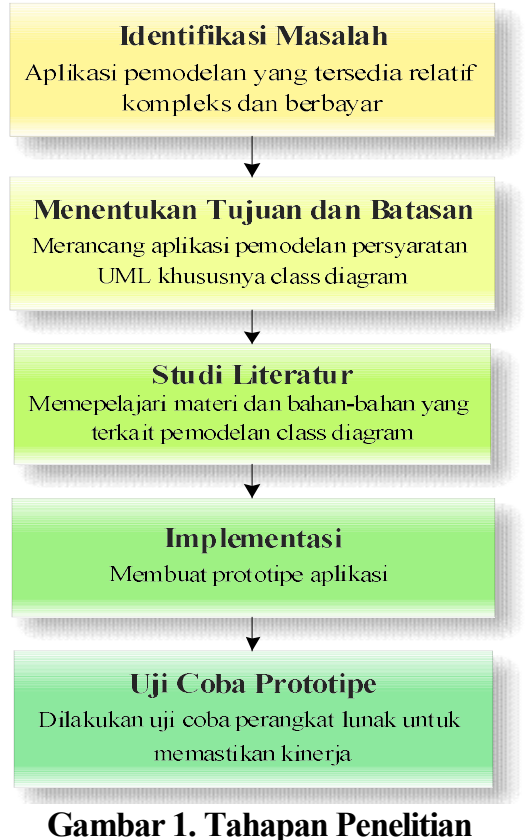




\section{HASIL DAN PEMBAHASAN}

Bagian hasil dan pembahasan meliputi analisis, perancangan, implementasi dan pengujian serta evaluasi aplikasi yang dibangun.

\subsection{Analisis}

Analisis dilakukan untuk mengetahui kebutuhan-kebutuhan apa yang diperlukan dalam sebuah aplikasi, dalam tabel 1 ditunjukkan kebutuhan fungsional aplikasi pemodelan kebutuhan.

Tabel 1. Kebutuhan fungsional

\begin{tabular}{cl}
\hline Kebutuhan & \multicolumn{1}{c}{ Deskripsi } \\
\hline Fungsional 1 & Sistem dapat menambahkan element class \\
Fungsional 2 & Sistem dapat menambahkan element generalitation \\
Fungsional 3 & Sistem dapat menambahkan element assosiation \\
Fungsional 4 & Sistem dapat menambahkan element multiplicity \\
Fungsional 5 & Sistem dapat menyimpan diagram dalam format jpg atau png \\
Fungsional 6 & Sistem dapat menampilkan studi kasus yang disediakan \\
\hline
\end{tabular}

Gambar 2 menunjukkan use case diagram aplikasi, terdapat satu orang aktor yakni pengguna. Sedangkan use case sistem terdiri dari use case memilih studi kasus, use case membuat class diagram, use case membuat diagram baru, dan use case menyimpan hasil diagram.

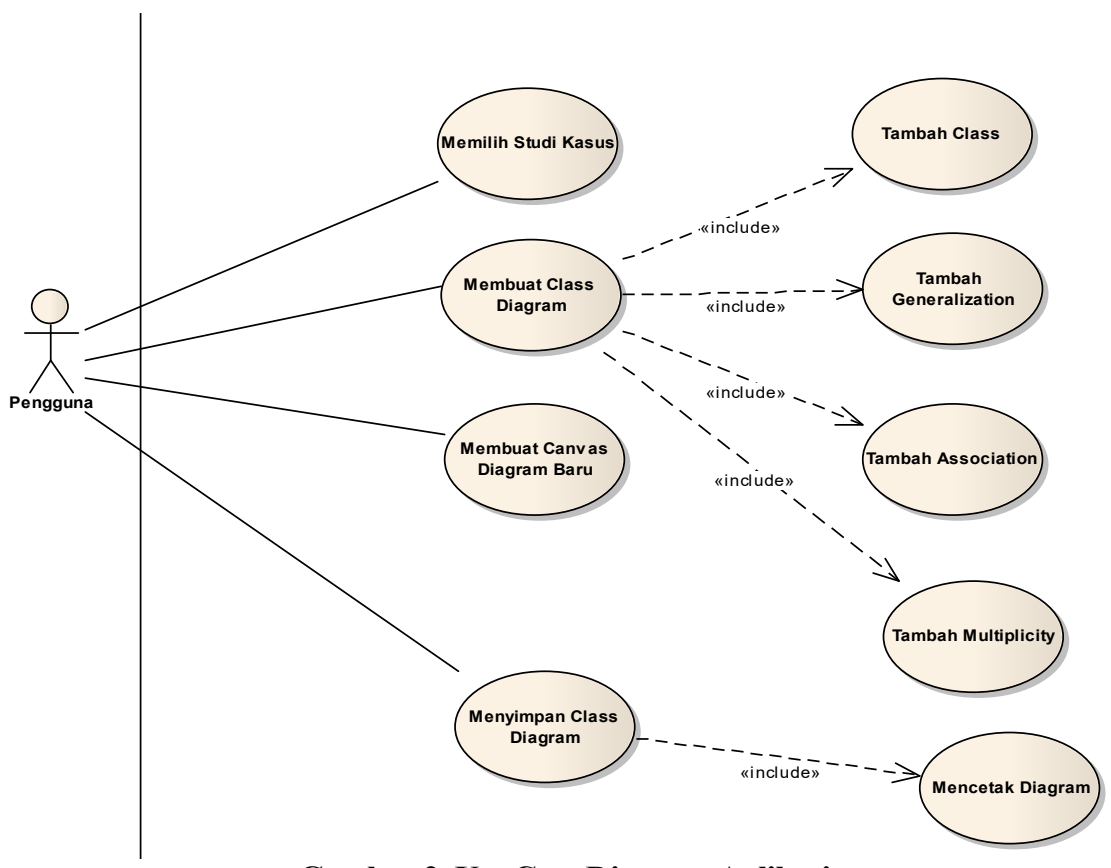

Gambar 2. Use Case Diagram Aplikasi

\subsection{Perancangan}

Perancangan dilakukan dengan melakukan perancangan antarmuka aplikasi. Gambar 3 menunjukkan halaman utama dari aplikasi yang terdiri dari tentang aplikasi dan bagaimana menggunakannya. Terdapat beberapa objek menu diantaranya adalah tentang aplikasi, tutorial aplikasi, dan demo aplikasi. 


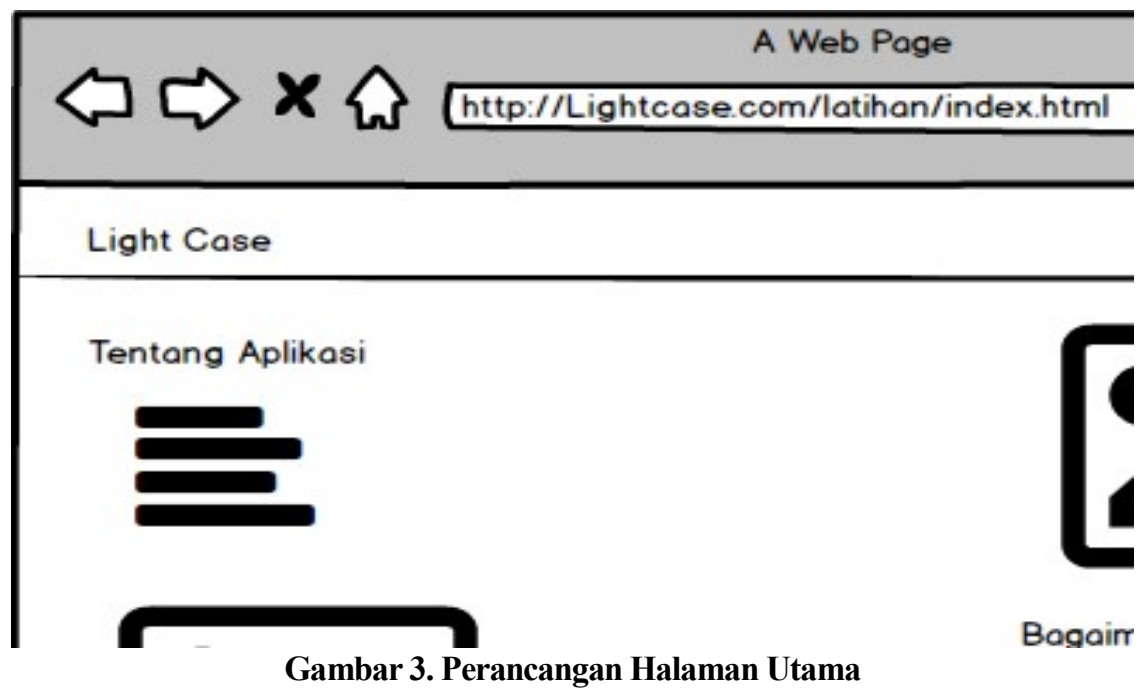

Gambar 4 menunjukkan perancangan halaman notasi, dalam halaman ini terdapat bagian notasi class diagram dan penjelasannya. Selain itu juga terdapat link menuju tentang aplikasi, tutorial dan demo.

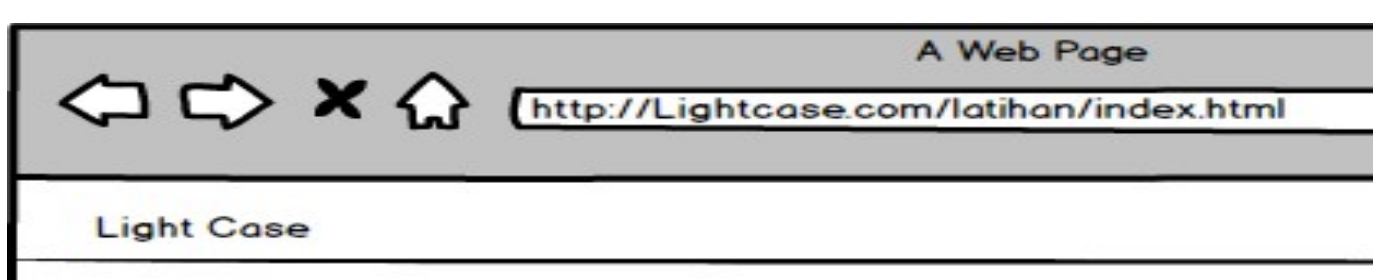

Class Diagram

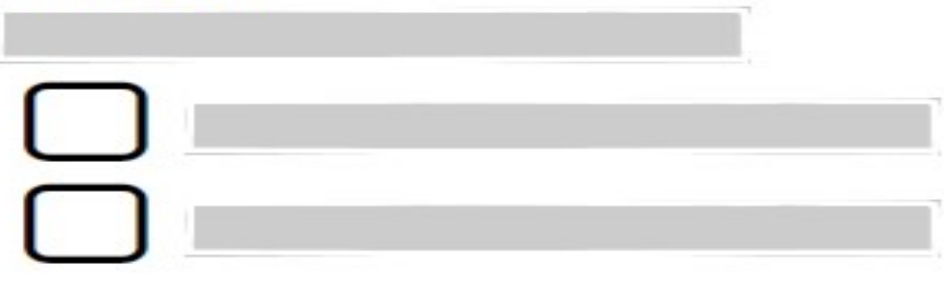

Gambar 4. Perancangan Halaman Notasi

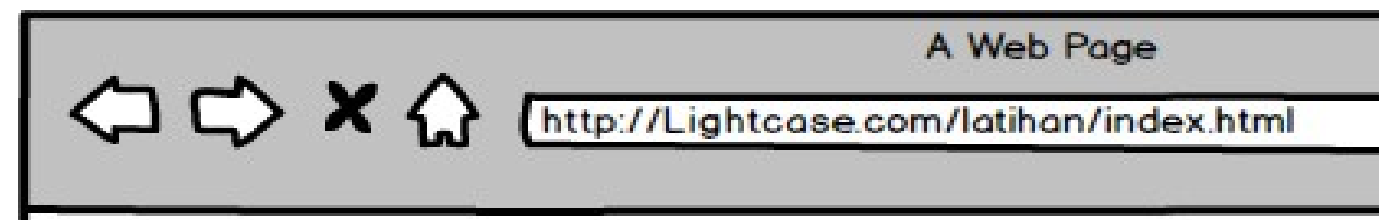

Light Case

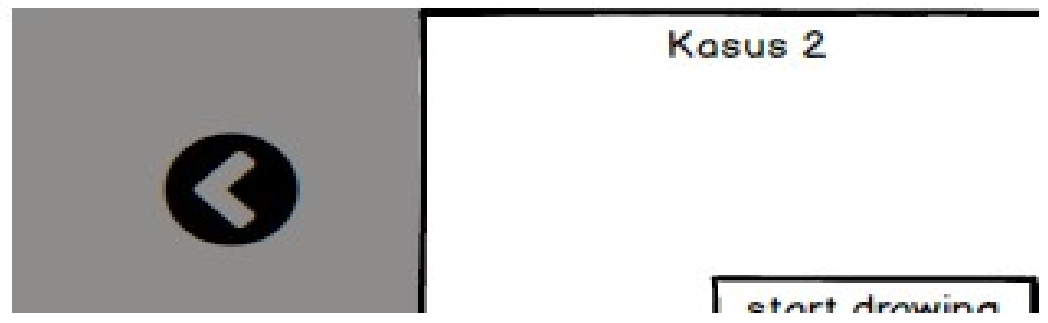

Gambar 5. Perancangan Halaman Pembuatan Diagram 
Gambar 5 menunjukkan perancangan halaman pembuatan diagram, terdapat tombol klik start drawing untuk memulai membuat diagram, kemudian pengguna dapat membuat class diagram sesuai notasi.

\subsection{Implementasi}

Implementasi adalaha melakukan pengkodean aplikasi, gambar 6 merupakan hasil implementasi halaman utama. Terdapat elemen notasi-notasi terkait class diagram beserta penjelasannya.

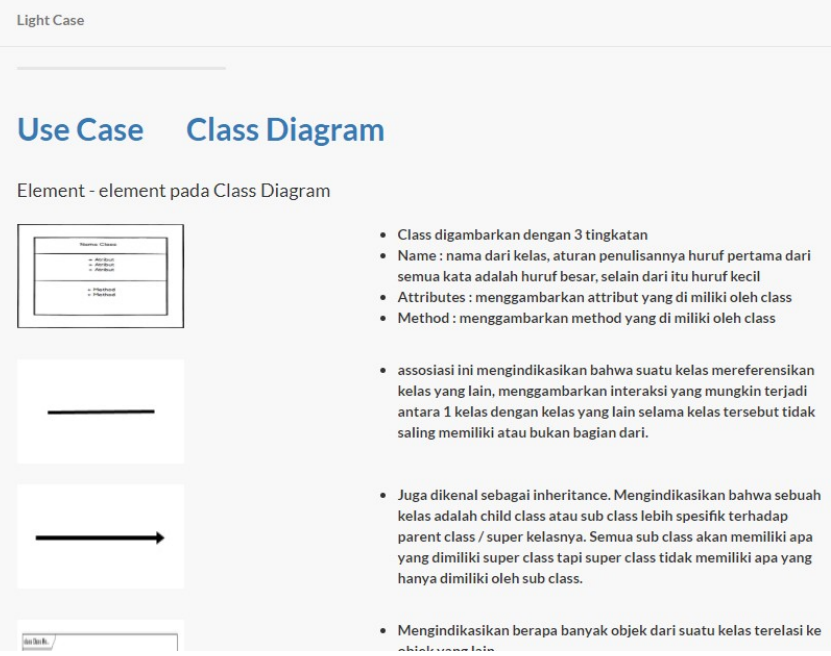

Gambar 6. Implementasi Halaman Utama

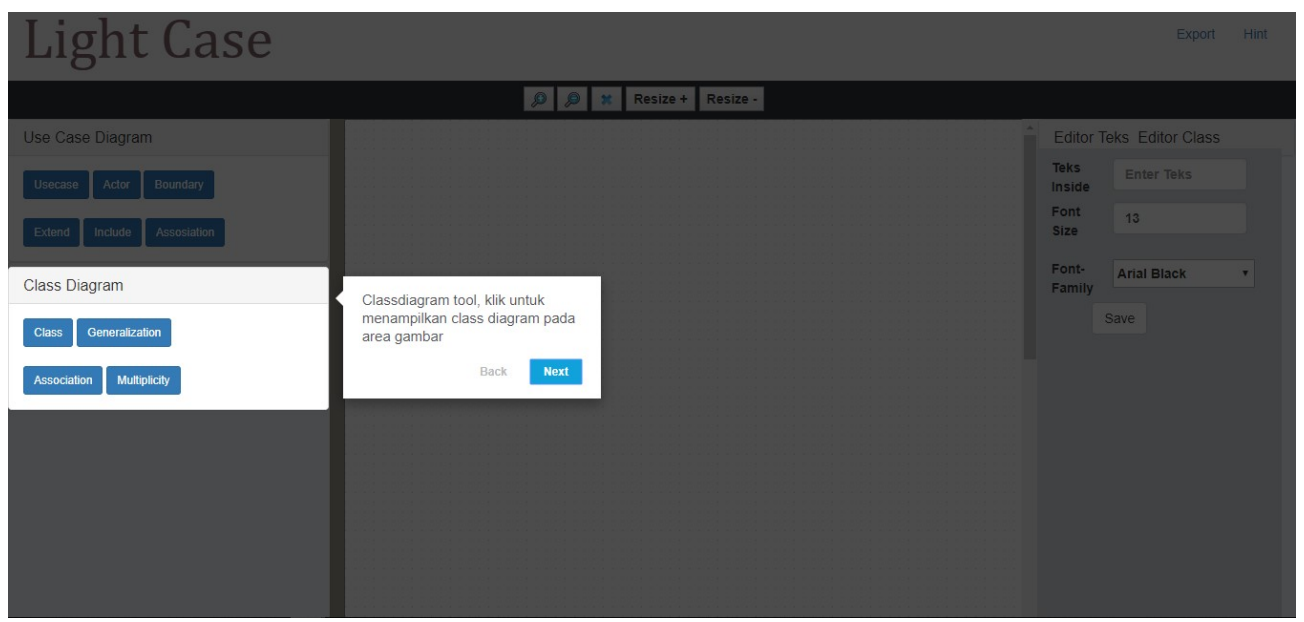

Gambar 7. Implementasi Halaman Area Kerja

Gambar 7 menunjukkan implementasi halaman area kerja, terdapat beberapa notasi seperti notasi class, notasi asosiasi, notasi generalisasi dan notasi multiplicity. Bagian tengah merupakan area kerja di mana dapat digunakan untuk membuat diagram. Sedangkan di bagian kanan terdapat editor teks untuk mengedit nama class, nama atribut, nama method, mengubah ukuran font dan mengubah jenis font. 


\section{Light Case}

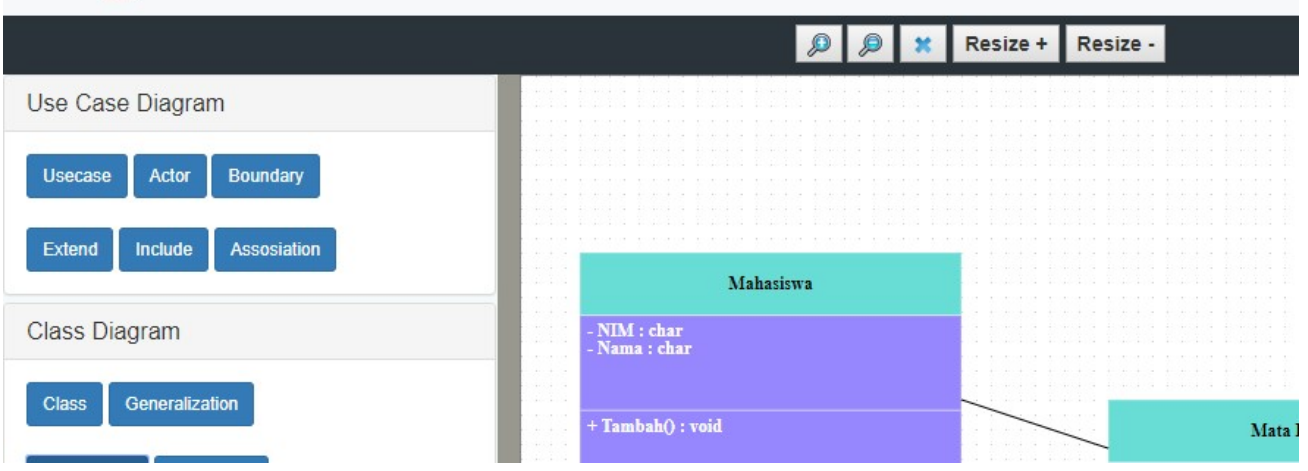

Gambar 8. Implementasi Halaman Pembuatan Diagram

Gambar 8 merupakan implementasi halaman pembuatan diagram, dalam gambar tersebut di contohkan cara pembuatan diagram yang mana sebelah kiri adalah notasi, tengah adalah area kerja pembuatan diagram dan kanan adalah editor teks.

\subsection{Pengujian}

Pengujian fungsionalitas aplikasi menggunakan pengujian black box. Teknik dan strategi pengujian terdapat dalam [7]. Terdapat beberapa fungsi yang diuji yang ditunjukkan dalam tabel 2 .

Tabel 2. Identifikasi dan rencana pengujian

\begin{tabular}{ccc}
\hline No & Nama Fungsi & Jenis Pengujian \\
\hline 1. & Tentang & Black Box \\
2. & Tutorial & Black Box \\
3. & Class & Black Box \\
4. & Demo & Black Box \\
5. & Pelajari & Black Box \\
6. & Export & Black Box \\
7. & Hint & Black Box \\
8. & Class Diagram & Black Box \\
9. & Tambah Class & Black Box \\
10. & Tambah Generalitation & Black Box \\
11. & Tambah Association & Black Box \\
12. & Tambah Multiplicity & Black Box \\
13. & Editor Text & Black Box \\
14. & Editor Class & Black Box \\
15. & Tambah nama class & Black Box \\
16. & Tambah Atribut & Black Box \\
17. & Tambah Method & BlackBox \\
\hline
\end{tabular}

Pengujian blackbox kemudian dilakukan sesuai dengan identifikasi, tabel 3 menunjukkan prosedur pengujian dan hasil atau kesimpulan pengujian secara black box.

Tabel 3. Prosedur dan hasil pengujian

\begin{tabular}{|c|c|c|c|c|c|}
\hline Identifikasi & Deskripsi & $\begin{array}{l}\text { Prosedur } \\
\text { Pengujian }\end{array}$ & Masukan & Keluaran & Kesimpulan \\
\hline Tentang & $\begin{array}{l}\text { Menampilkan } \\
\text { halaman tentang. }\end{array}$ & $\begin{array}{l}\text { Mengklik } \\
\text { button tentang }\end{array}$ & Klik & $\begin{array}{l}\text { Halaman } \\
\text { tentang }\end{array}$ & Diterima \\
\hline Tutorial & $\begin{array}{l}\text { Menampilkan } \\
\text { tutorial tentang }\end{array}$ & $\begin{array}{l}\text { Mengklik } \\
\text { button tutorial }\end{array}$ & Klik & $\begin{array}{l}\text { Halaman } \\
\text { tutorial }\end{array}$ & Diterima \\
\hline Class & $\begin{array}{l}\text { Menampilkan } \\
\text { halaman tutorial }\end{array}$ & $\begin{array}{l}\text { Mengklik } \\
\text { button class }\end{array}$ & Klik & $\begin{array}{l}\text { Halaman } \\
\text { tutorial }\end{array}$ & Diterima \\
\hline
\end{tabular}




\begin{tabular}{|c|c|c|c|c|c|}
\hline Identifikasi & Deskripsi & $\begin{array}{l}\text { Prosedur } \\
\text { Pengujian }\end{array}$ & Masukan & Keluaran & Kesimpulan \\
\hline Demo & $\begin{array}{l}\text { Menampilkan } \\
\text { halaman kasus dan }\end{array}$ & $\begin{array}{l}\text { Klik button } \\
\text { demo }\end{array}$ & Klik & $\begin{array}{l}\text { Halaman } \\
\text { kasus }\end{array}$ & Diterima \\
\hline Pelajari & $\begin{array}{l}\text { Menampilkan } \\
\text { halaman cara }\end{array}$ & $\begin{array}{l}\text { Klik button } \\
\text { pelajari }\end{array}$ & Klik & $\begin{array}{l}\text { Halaman } \\
\text { penggunaa }\end{array}$ & Diterima \\
\hline Export & $\begin{array}{l}\text { Menampilkan } \\
\text { halaman diagram }\end{array}$ & $\begin{array}{l}\text { Klik button } \\
\text { export }\end{array}$ & Klik & $\begin{array}{l}\text { Halaman } \\
\text { diagram }\end{array}$ & Diterima \\
\hline Hint & $\begin{array}{l}\text { Menampilkan } \\
\text { bantuan dalam }\end{array}$ & $\begin{array}{l}\text { Klik button } \\
\text { hint }\end{array}$ & Klik & $\begin{array}{l}\text { Pop up } \\
\text { bantuan }\end{array}$ & Diterima \\
\hline $\begin{array}{l}\text { Class } \\
\text { Diagram }\end{array}$ & $\begin{array}{l}\text { Menampilkan menu } \\
\text { class }\end{array}$ & $\begin{array}{l}\text { Klik button } \\
\text { class diagram }\end{array}$ & Klik & $\begin{array}{l}\text { Menu class } \\
\text { diagram }\end{array}$ & Diterima \\
\hline $\begin{array}{l}\text { Tambah } \\
\text { Class }\end{array}$ & $\begin{array}{l}\text { Menampilkan dan } \\
\text { menambah class }\end{array}$ & $\begin{array}{l}\text { Klik button } \\
\text { class }\end{array}$ & $\begin{array}{l}\text { Drag and } \\
\text { Drop }\end{array}$ & $\begin{array}{l}\text { Tampilan } \\
\text { class }\end{array}$ & Diterima \\
\hline $\begin{array}{l}\text { Tambah } \\
\text { Generalitati }\end{array}$ & $\begin{array}{l}\text { Menampilkan } \\
\text { generalitation }\end{array}$ & $\begin{array}{l}\text { Klik button } \\
\text { generalitation }\end{array}$ & $\begin{array}{l}\text { Drag and } \\
\text { Drop }\end{array}$ & $\begin{array}{l}\text { Tampilan } \\
\text { generalitati }\end{array}$ & Diterima \\
\hline $\begin{array}{l}\text { Tambah } \\
\text { Association }\end{array}$ & $\begin{array}{l}\text { Menambah } \\
\text { association }\end{array}$ & $\begin{array}{l}\text { Klik button } \\
\text { association }\end{array}$ & $\begin{array}{l}\text { Drag and } \\
\text { Drop }\end{array}$ & $\begin{array}{l}\text { Tampilan } \\
\text { association }\end{array}$ & Diterima \\
\hline $\begin{array}{l}\text { Tambah } \\
\text { Multiplicity }\end{array}$ & $\begin{array}{l}\text { Menambah } \\
\text { multiplycity }\end{array}$ & $\begin{array}{l}\text { Klik button } \\
\text { multiplycity }\end{array}$ & $\begin{array}{l}\text { Drag and } \\
\text { Drop }\end{array}$ & $\begin{array}{l}\text { Tampilan } \\
\text { Multiplycit }\end{array}$ & Diterima \\
\hline Editor Text & $\begin{array}{l}\text { Menampilkan menu } \\
\text { untuk edit usecase }\end{array}$ & $\begin{array}{l}\text { Klik button } \\
\text { editor text }\end{array}$ & Edit Text & $\begin{array}{l}\text { Tampilan } \\
\text { menu edit }\end{array}$ & Diterima \\
\hline Editor Class & $\begin{array}{l}\text { Menampilkan menu } \\
\text { untuk class }\end{array}$ & $\begin{array}{l}\text { Klik button } \\
\text { editor class }\end{array}$ & Edit Text & $\begin{array}{l}\text { Tampilan } \\
\text { menu edit }\end{array}$ & Diterima \\
\hline $\begin{array}{l}\text { Edit nama } \\
\text { class }\end{array}$ & Mengedit nama class & $\begin{array}{l}\text { Ketik nama } \\
\text { class }\end{array}$ & Edit Text & $\begin{array}{l}\text { Tampilan } \\
\text { edit nama }\end{array}$ & Diterima \\
\hline $\begin{array}{l}\text { Tambah } \\
\text { Atribut }\end{array}$ & $\begin{array}{l}\text { Menambahkan } \\
\text { atribut }\end{array}$ & $\begin{array}{l}\text { Ketik nama } \\
\text { atribut baru }\end{array}$ & $\begin{array}{l}\text { Drag and } \\
\text { Drop }\end{array}$ & $\begin{array}{l}\text { Tampilan } \\
\text { tambah }\end{array}$ & Diterima \\
\hline $\begin{array}{l}\text { Tambah } \\
\text { Method }\end{array}$ & $\begin{array}{l}\text { Menambahkan } \\
\text { method }\end{array}$ & $\begin{array}{l}\text { Klik Method } \\
\text { Ketik nama }\end{array}$ & $\begin{array}{l}\text { Drag and } \\
\text { Drop }\end{array}$ & $\begin{array}{l}\text { Tampilan } \\
\text { Tambah }\end{array}$ & Diterima \\
\hline
\end{tabular}

Berdasarkan hasil pengujian dari tabel 3 di atas didapatkan bahwa semua fungsi sudah lolos uji dengan pengujian black box, sehingga dapat disimpulkan bahwa 100\% fungsi sudah sesuai harapan tanpa adanya error. Selanjutnya pengujian dilakukan kepada pengguna aplikasi dengan memberikan kuisioner kepada 30 orang responden. Responden diberikan 10 pertanyaan dengan skala Likert 1-5. Skala likert mencakup parameter sangat setuju (SS), setuju (S), netral (N), tidak setuju (TS), dan sangat tidak setuju (STS). Prosentase kemudian akan didapatkan berdasrkan jumlah perhitungan poin rata-rata dibagi dengan jumlah parameter.

Tabel 4. Kuisioner

\begin{tabular}{llccccc}
\hline No & \multicolumn{1}{c}{ Pernyataan } & SS & $\boldsymbol{S}$ & $\boldsymbol{N}$ & TS & STS \\
\hline 1 & Aplikasi mudah digunakan & 10 & 20 & 0 & 1 & 0 \\
2 & Notasi class diagram mudah dipahami & 10 & 18 & 0 & 3 & 0 \\
3 & Aplikasi responsive & 15 & 12 & 0 & 4 & 0 \\
4 & Aplikasi mampu membantu mengenalkan class diagram & 13 & 12 & 0 & 4 & 1 \\
5 & Antarmuka menarik & 10 & 19 & 0 & 1 & 1 \\
6 & Antarmuka mudah dipahami & 8 & 16 & 0 & 6 & 1 \\
7 & Aplikasi membantu pengguna mengubah dan memodifikasi & 9 & 19 & 0 & 3 & 0 \\
8 & Saya senang dengan antarmuka aplikasi & 10 & 15 & 0 & 6 & 0 \\
9 & Saya senang dengan fungsionalitas aplikasi & 11 & 18 & 0 & 2 & 0 \\
10 & Saya senang dengan class diagram yang dibuat & 16 & 10 & 0 & 5 & 0 \\
\hline
\end{tabular}

Hasil kuisioner ditunjukkan dalam tabel 4, terdapat 10 pernyataan dengan tiga parameter yakni pernyataan 1-4 adalah pernyataan kinerja aplikasi, pernyataan 5-7 adalah pernyataan kinerja kemudahan penggunaan, dan pernyataan 8-10 adalah pernyataan kepuasan pengguna.

Gambar 9 menunjukkan grafik hasil pengujian penerimaan pengguna, berdasarkan hasil kuisioner didapatkan bahwa $92 \%$ responden sangat setuju dan setuju bahwa aplikasi memiliki kinerja yang baik, 
$90 \%$ sangat setuju dan setuju bahwa system mudah digunakan dan $89 \%$ responden puas dengan aplikasi yang dibangun.

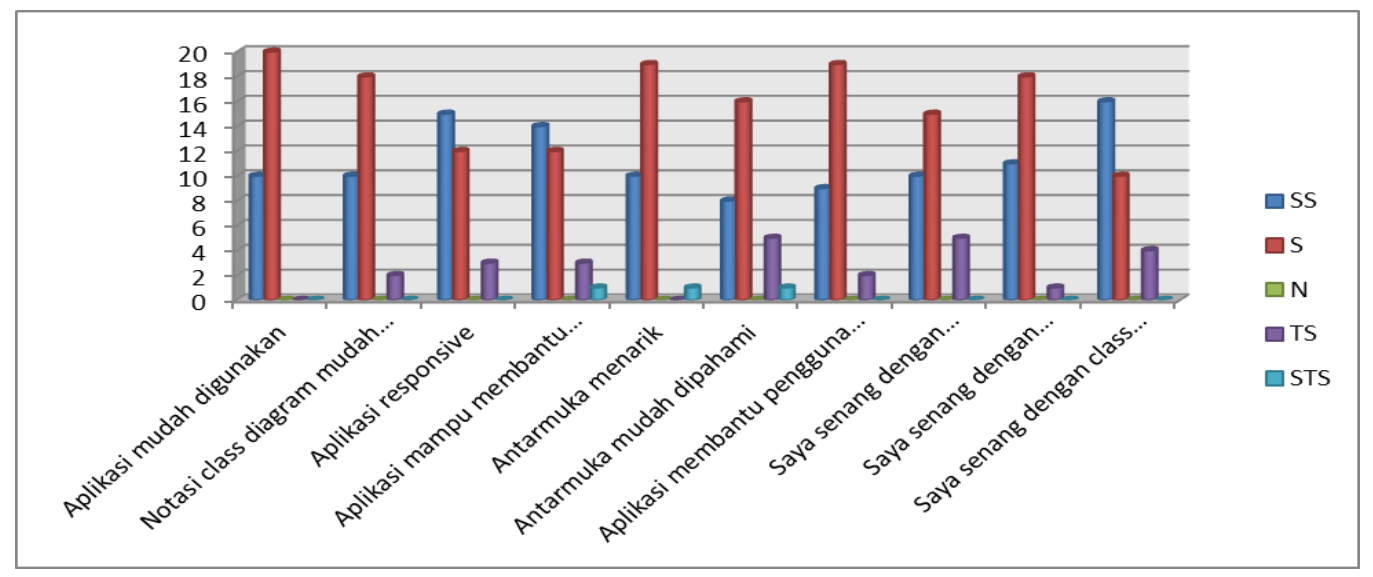

\section{KESIMPULAN}

Gambar 9. Grafik Hasil Pengujian User Acceptance

Class diagram merupakan salah satu diagram yang etrdapat dalam UML. Dalam tahap analisis terdapat bagian untuk memodelkan masalah dengan visualisasi berupa diagram. Banyaknya aplikasi yang beredar dewasa ini memiliki kompleksitas serta kekurangan dan kelebihan masing masing. Dalam penelitian ini telah dilakukan perancangan dan pembangunan prototipe aplikasi untuk memodelkan class diagram. Aplikasi yang dibangun berbasis web dan tidak memerlukan instalasi. Berdasarkan hasil pengujian didapatkan bahwa fungsionalitas aplikasi telah berjalan dan tidak ditemukan error. Sedangkan berdasarkan hasil evaluasi pengguna didapatkan bahwa aplikasi yang dibangun mayoritas pengguna puas dengan kinerja aplikasi, kemudahan penggunaan dan puas terhadap keseluruhan fungsionalitas dan antarmuka aplikasi.

\section{UCAPAN TERIMA KASIH}

Penulis mengucapkan terima kasih pada LPPM Udinus Semarang yang telah memberikan dukungan finansial terhadap penelitian ini, terimakasih juga diucapkan untuk editor, reviewer, dan semua pihak yang telah membantu dalam penyelesaian artikel ini.

\section{DAFTAR PUSTAKA}

[1] E. R. Subhiyakto, M. Kamalrudin, S. Sidek, and S. S. S. Ahmad, "Customization of Requirements Modelling Tools for Software Engineering Education,” Int. Symp. Res. Innov. Sustain. 2014, vol. 26, no. 4, pp. 1581-1584, 2014.

[2] R. Pressman, Rekayasa Perangkat Lunak: Pendekatan Praktisi Buku I. Yogyakarta, 2015.

[3] L. Khaled, "A Comparison between UML Tools," 2009 Second Int. Conf. Environ. Comput. Sci., pp. 111-114, 2009.

[4] E. R. Subhiyakto and D. W. Utomo, "RMTool; Sebuah Aplikasi Pemodelan Persyaratan Perangkat Lunak menggunakan UML," JNTETI, vol. 6, no. 3, pp. 268-274, 2017.

[5] M. Subekti, D. Indrawan, and G. Putra, "Perancangan Case Tools untuk Diagram Use Case, Activity, dan Class untuk Permodelan UML Berbasis Web Menggunakan HTML5 dan PHP," ComTech, vol. 5, no. 2, pp. 625-635, 2014.

[6] D. R. Stikkolorum, T. Ho-quang, and Chaudron M.R.V, "Revealing Students ' UML Class Diagram Modelling Strategies with WebUML and LogViz," in 41st Euromicro Conference on Software Engineering and Advanced Applications Revealing, 2015.

[7] E. R. Subhiyakto and D. W. Utomo, "Software Testing Techniques and Strategies Use in Novice Software Teams," J. Sist. Inf., 2016. 